\title{
The impact of COVID-19 pandemic on cardiac surgery in Israel
}

\author{
Eitan Keizman ${ }^{1,2^{*}+}$, Eilon Ram ${ }^{1 \dagger}$, Erez Kachel ${ }^{1,2}$, Leonid Sternik ${ }^{1}$ and Ehud Raanani ${ }^{1}$
}

\begin{abstract}
Background: Ever since the coronavirus disease 2019 (COVID-19) has become a pandemic, worldwide efforts are being made to "flatten the curve". Israel was amongst the first countries to impose significant restrictions. As a result, cardiac surgeons have been required to scale down their routine practice, resulting in a significant reduction in the number of cardiac surgeries. The aim of this study is to characterize the impact of COVID-19 on cardiac surgery in Israel.

Methods: This is a retrospective observational study performed in two cardiac surgery departments in Israel and includes all patients who underwent cardiac surgery in March and April during the years 2019 and 2020. The patient cohort was divided into two groups based on the year of operation. Analysis of the patients' baseline characteristics, operative data, and postoperative outcome, was performed.

Results: The 2019 group $(n=173)$, and the 2020 group $(n=108)$ were similar regarding their baseline characteristics, previous medical history, and rates of previous revascularization interventions. However, compared to the 2019 group, patients in the 2020 group were found to be more symptomatic (NYHA class IV; 2.4\% vs. 6.2\%, $p=0.007)$. While all patients underwent similar procedures, patients in the 2020 group had significantly longer procedural time $(p<0.001)$. In-hospital mortality rate was found to be significantly higher in group $2020(13 \%$ vs. $5.2 \%, p=0.037)$.
\end{abstract}

Conclusions: While the number of patients undergoing cardiac surgery declined during the outbreak period, the rate of surgical mortality increased. One explanation for this might be delayed hospital arrival.

Keywords: Cardiac surgery, COVID-19

\section{Introduction}

Towards the end of 2019 a new disease emerged in Wuhan, China, now known as coronavirus disease 2019 (COVID-19), caused by severe acute respiratory syndrome coronavirus 2 (SARS-CoV-2) [1-3]. Approximately 3 months later, on March 11, 2020, COVID-19 was announced by the World Health Organization as a

\footnotetext{
* Correspondence: eitan.keizman@gmail.com

†Eitan Keizman and Eilon Ram contributed equally to this work.

${ }^{1}$ Department of Cardia cSurgery, The Leviev Cardiothoracic and Vascular Center, Sheba Medical Center, Affiliated to the Sackler School of Medicine, Tel Aviv University, Ramat-Gan, Israel

${ }^{2}$ Department of Cardiac Surgery, The Baruch Padeh Medical Center, 52621 Tiberias, Israel
}

global pandemic. As of May 20, 2020, more than five million people worldwide were affected by the virus with about 325,000 deaths. Since the beginning of COVID-19 the world has changed drastically, and various measures have been taken in an attempt to "flatten the curve", some of them having an unprecedented effect on world health systems [4].

Israel was amongst the first countries to close its borders and impose significant restrictions on its population, comprising personal movement restrictions, social distancing and cancellation of public transportation. In early March, schools and stores were closed, and dedicated units to treat COVID-19 patients were inaugurated. By the time COVID-19 was declared a pandemic,

C The Author(s). 2020 Open Access This article is licensed under a Creative Commons Attribution 4.0 International License, which permits use, sharing, adaptation, distribution and reproduction in any medium or format, as long as you give appropriate credit to the original author(s) and the source, provide a link to the Creative Commons licence, and indicate if changes were made. The images or other third party material in this article are included in the article's Creative Commons licence, unless indicated otherwise in a credit line to the material. If material is not included in the article's Creative Commons licence and your intended use is not permitted by statutory regulation or exceeds the permitted use, you will need to obtain permission directly from the copyright holder. To view a copy of this licence, visit http://creativecommons.org/licenses/by/4.0/ The Creative Commons Public Domain Dedication waiver (http://creativecommons.org/publicdomain/zero/1.0/) applies to the data made available in this article, unless otherwise stated in a credit line to the data. 
it had affected approximately 200 people countrywide with no fatalities.

Being a small country, one of the primary goals of the system was to anticipate the influx of patients arriving at medical centers in order to prevent a collapse of medical resources, including exhaustion of personnel, lack of equipment, protective gear, mechanical ventilators, surgical drapes, and extracorporeal membrane oxygenation (ECMO) machines. Virtually all medical specialties were required to significantly reduce their daily routine services. Specifically, cardiac surgeons were requested to scale down their clinical practice and adapt to a new hospital policy [4-6]. As a result, cardiac surgical programs engaged into a new reality of patient selection, prioritizing urgent cases while delaying elective procedures. Similar circumstances are reported worldwide $[1,4,5,7]$. Additionally, from fear of getting infected, a new phenomenon of avoiding medical care emerged, and thus, non-COVID19 patients requiring cardiac surgery refrained from requesting help.

While the number of patients undergoing cardiac surgery compared with previous years has undoubtedly decreased, the actual impact of this decline is yet to be fully understood. Therefore, the aim of this study is to characterize the impact of COVID-19 on cardiac surgery discipline by comparing the same time periods from different years within two major cardiac surgery departments in Israel.

\section{Methods}

This is a retrospective observational study performed in two cardiac surgery departments in Israel: the Leviev Heart Center, Sheba Medical Center, Tel Hashomer, the largest tertiary hospital in Israel, located in the center of the country, and the Baruch Padeh Medical Center, Poriya, which is located in the north of the country.

All patients undergoing cardiac surgery between March 1 and April 30 during the years 2019 and 2020 were included in the cohort. No exclusion criteria applied. The patients were divided into two groups based on the year in which they underwent surgery. The decision to investigate specifically March and April was based on the fact that the strict limitations came into force at the beginning of March and continued throughout those 2 months.

A careful analysis of the patients' baseline characteristics, operative data, and postoperative outcomes, was performed by two separate researchers. The data reviewed included hospitalization records, outpatient clinic visits, and the records of local and referring physicians. Throughout the study period, all procedures were performed and completed by the same surgical and anesthesiology teams.

\section{Statistical analysis}

Data are presented as mean \pm standard deviation. Continuous variables were tested with the KolmogorovSmirnov test for normal distribution. Categorical variables are given as frequencies and percentages. A chisquare test was used for comparison of categorical variables between the groups. Student's t-test was performed for comparison of normally distributed continuous variables and Mann-Whitney $U$ test for non-normal distribution. Statistical significance was assumed when the null hypothesis could be rejected at $P<0.05$. All $P$-values are the results of two-sided tests. Statistical analyses were conducted using $\mathrm{R}$ (version 3.4.1).

\section{Results}

\section{Baseline characteristics and operative data}

The 2019 group included 173 patients, while group 2020 included 108 patients, accounting for a reduction in cases of more than a third from the previous year (37.5\%). Baseline characteristics of patients in both groups were similar. The mean age was $64 \pm 14$ years and $70 \%$ were men. Furthermore, both groups were similar in terms of previous medical history and preexisting conditions including hypertension, dyslipidemia, diabetes mellitus, insulin dependence, chronic renal failure, dialysis therapy, peripheral vascular disease, chronic obstructive pulmonary disease, pulmonary hypertension, prior cerebral event, previous cardiac surgery and atrial fibrillation (Table 1). Both groups had similar rates of previous revascularization interventions including both percutaneous cardiac intervention (PCI) and coronary artery bypass graft (CABG). However, there was a trend toward a higher EuroSCORE in the 2020 compared to the 2019 group (Table 1). Additionally, compared to the 2019 group, patients in the 2020 group were found to have more severe symptoms, reflected by higher New York Heart Association (NYHA) functional class IV ( $2.4 \%$ vs. $6.2 \%, p=0.007$ ).

While patients from both years underwent similar surgical procedures, patients in the 2020 group had significantly longer cross-clamp time (68 \pm 30 vs. $107 \pm 88 \mathrm{~min}$, $p=0.005$ ) (Table 2).

\section{Postoperative outcomes}

The major finding was the in-hospital mortality rate, which was found to be significantly higher in group 2020, with $14(13.0 \%)$ deaths versus 9 (5.2\%) deaths in $2019(p=0.037)$. While there was no emergency reopening for bleeding or tamponade in 2020, 8 patients required surgical revision in $2019(4.7 \%)(p=0.058)$. There were no significant differences between the groups regarding other postoperative complications, which included: stroke, acute respiratory distress syndrome (ARDS), heart failure, acute kidney injury, atrial 
Table 1 Baseline characteristics

\begin{tabular}{|c|c|c|c|}
\hline & $\begin{array}{l}2019 \text { Group } \\
N=173\end{array}$ & $\begin{array}{l}2020 \text { Group } \\
N=108\end{array}$ & $p$-value \\
\hline Age (mean $\pm S D)$ & $63.5 \pm 13.5$ & $64 \pm 13.7$ & 0.765 \\
\hline Gender (male) (\%) & $128 \pm 74$ & $69 \pm 63.9$ & 0.096 \\
\hline Height (mean \pm SD) & $168.9 \pm 17.3$ & $166.4 \pm 16.2$ & 0.251 \\
\hline Weight (mean \pm SD) & $78.6 \pm 16.5$ & $80.4 \pm 21$ & 0.440 \\
\hline $\mathrm{BMI}($ mean $\pm \mathrm{SD})$ & $41.8 \pm 183.5$ & $31.4 \pm 25.9$ & 0.592 \\
\hline Obesity (\%) & $91(53)$ & $54(61)$ & 0.287 \\
\hline Hypertension (\%) & $112(66)$ & $61(71)$ & 0.501 \\
\hline PVD (\%) & $14(8)$ & $5(8.2)$ & 1.000 \\
\hline Diabetes (\%) & $68(39)$ & $40(46)$ & 0.370 \\
\hline Insulin treatment (\%) & $2(7)$ & $1(7.7)$ & 1.000 \\
\hline Hyperlipidemia (\%) & $109(65)$ & $57(66)$ & 0.984 \\
\hline Atrial fibrillation (\%) & $102(59)$ & $52(58)$ & 1.000 \\
\hline Previous MI (\%) & $18(58)$ & $10(77)$ & 0.399 \\
\hline Previous revascularization (\%) & & & 0.087 \\
\hline None & $28(90)$ & $9(69)$ & \\
\hline $\mathrm{PCl}$ & $2(7)$ & $4(31)$ & \\
\hline CABG & $1(3)$ & $0(0)$ & \\
\hline Renal impairment (\%) & $12(7)$ & $12(14)$ & 0.126 \\
\hline Baseline creatinine (mean $\pm S D$ ) & $1.05 \pm 0.63$ & $1.2 \pm 0.95$ & 0.160 \\
\hline COPD (\%) & $14(8)$ & $11(14)$ & 0.272 \\
\hline Prior stroke(\%) & $14(8)$ & $3(3)$ & 0.223 \\
\hline Dialysis (\%) & $1(0.6)$ & $2(2.3)$ & 0.552 \\
\hline Previous cardiac operation (\%) & $3(10)$ & $1(8)$ & 1.000 \\
\hline Pulmonary hypertension (> 60 mmHg) (\%) & $0(0)$ & $2(15)$ & 0.149 \\
\hline $\operatorname{LVEF}(\%)($ mean $\pm \mathrm{SD})$ & $52 \pm 13.4$ & $52.2 \pm 13.6$ & 0.903 \\
\hline NYHA functional class IV (\%) & $4(2)$ & $6(6)$ & 0.007 \\
\hline EuroSCORE (standard) $($ mean \pm SD) & $4.89 \pm 2.78$ & $5.73 \pm 3.56$ & 0.086 \\
\hline EuroSCORE (logistic) (mean \pm SD) & $5.41 \pm 7.68$ & $7.78 \pm 11.47$ & 0.098 \\
\hline
\end{tabular}

SD Standard deviation, BMI Body mass index, PVD Peripheral vascular disease, MI Myocardial infarction, $P C I$ Percutaneous coronary intervention, CABG Coronary artery bypass grafting, COPD Chronic obstructive pulmonary disease, LVEF Left ventricle ejection fraction, NYHA New York Heart Association

fibrillation, permanent pacemaker implantation, and wound infection (Table 3). All patients in the 2020 cohort tested negative for COVID-19 during hospitalization prior to operation.

\section{Discussion}

The developed world is currently facing what seems to be a watershed, and no doubt one of the significant landmarks in the history of medicine. One of the greatest challenges of the medical community is the scarcity of knowledge and experience in facing this virus $[2,3]$.

Apart from the common typical viral symptoms (i.e. fever, cough, fatigue, dyspnea, and diarrhea) or, in more severe cases, pneumonia and ARDS, COVID-19 also has some significant consequences on the cardiovascular system and the management of cardiovascular patients. The first association between COVID-19 and the cardiovascular system is the increased risk in patients with pre-existing cardiovascular disease to develop severe disease and death. Second, complications such as myocarditis [8-10] acute myocardial infarction [11], arrhythmias [9], thromboembolic events [12-14], and heart failure [11, 14], have been linked to COVID-19 infection. In some cases, these complications engendered treatment with ECMO [15-17]. Third, reports on cardiovascular side effects of COVID-19 therapies have been published [18-20], and lastly, the pandemic's consequences regarding non-COVID-19 cardiovascular patients. New policies have affected virtually each and every medical discipline, specifically those of surgeons in various fields who were required to apply a triage never before seen in their daily routine practice $[3,6,7]$. Meanwhile, increasing numbers of patients are avoiding medical care 
Table 2 Surgical procedures

\begin{tabular}{llll}
\hline & $\begin{array}{l}\text { 2019 Group } \\
\mathbf{N = 1 7 3}\end{array}$ & $\begin{array}{l}\mathbf{2 0 2 0} \text { Group } \\
\mathbf{N = 1 0 8}\end{array}$ & $\boldsymbol{p}$-value \\
\hline AVR (\%) & $45(26.0)$ & $24(22.2)$ & 0.565 \\
MVR/MVr (\%) & $31(17.9)$ & $25(23.1)$ & 0.361 \\
TVr (\%) & $13(7.5)$ & $4(3.7)$ & 0.295 \\
Ascending aorta repair (\%) & $17(9.8)$ & $6(5.6)$ & 0.295 \\
Dissection repair (\%) & $4(2.3)$ & $2(1.9)$ & 1.000 \\
MAZE procedure (\%) & $4(2.3)$ & $6(5.6)$ & 0.273 \\
CABG (\%) & $87(50.3)$ & $54(50.0)$ & 1.000 \\
Number of total grafts (\%) & & & 0.217 \\
$\quad 1$ & $18(24.0)$ & $8(15.4)$ & \\
2 & $29(38.7)$ & $15(28.8)$ & \\
3 & $21(28.0)$ & $23(44.2)$ & \\
4 & $7(9.3)$ & $6(11.5)$ & \\
Cross clamp time, minutes (\%) & $68.4(30.5)$ & $107.4(87.6)$ & 0.005
\end{tabular}

AVR Aortic valve replacement, $M V R$ Mitral valve replacement, $M V r$ Mitral valve repair, $T V r$ Tricuspid valve repair, CABG coronary artery bypass graft

while being symptomatic at home. As the pandemic is still ongoing, the aftermath remains largely unclear, with emerging reports of patients deteriorating or dying at home. However, it will be difficult to quantify the impact of nonCOVID-19 morbidity and mortality during the COVID-19 pandemic. While the number of infected patients is objectively quantifiable, the number of non-COVID-19 patients suffering from the outbreak's consequences is far from being measurable. In other words, the impact of the virus is not solely from personally transmitted infection.

One of the aspects of this may be illustrated in the field of cardiac surgery. At the beginning of the outbreak, Légaréet al., on behalf of the Canadian Society of Cardiac Surgeons (CSCS), released a guidance statement to cardiac surgeons. They suggested a template for triaging patients based on the percentage in reduction of services. According to their suggestion, upon a mild reduction in services $(0-30 \%)$, only symptomatic outpatients or those at greater risk for developing adverse events, should undergo surgery alongside the urgent cases. Under a $>50 \%$ reduction in services, they suggested operating on urgent cases only $[4,7]$.

Israel was one of the first responders to the crisis, and consequently there has been a significant reduction in the number of cardiac surgeries performed. Evidently, characterizing the preoperative status of the entire patient cohort, those of the COVID-19 era were not necessarily sicker, but rather more symptomatic. Coincidentally or not, this correlates with the CSCS recommendation, although no guidance statement has been released by the Israel Society of Cardiothoracic Surgery.

Table 3 Postoperative Outcomes

\begin{tabular}{|c|c|c|c|}
\hline & $\begin{array}{l}2019 \text { Group } \\
N=173\end{array}$ & $\begin{array}{l}2020 \text { Group } \\
N=108\end{array}$ & $p$-value \\
\hline In-hospital mortality (\%) & $9(5.2)$ & $14(13.0)$ & 0.037 \\
\hline Revision (\%) & $8(4.7)$ & $0(0.0)$ & 0.058 \\
\hline Stroke (\%) & $0(0)$ & $0(0)$ & 1.000 \\
\hline AKI (\%) & & & 0.233 \\
\hline Up to: mild & $170(98.8)$ & $104(97.2)$ & \\
\hline moderate & $1(0.6)$ & $3(2.8)$ & \\
\hline severe & $1(0.6)$ & $0(0.0)$ & \\
\hline ARDS (\%) & $1(3.3)$ & $2(16.7)$ & 0.394 \\
\hline $\mathrm{AF}(\%)$ & $48(27.9)$ & $20(22.2)$ & 0.396 \\
\hline PPS (\%) & $20(11.6)$ & $13(14.4)$ & 0.648 \\
\hline HF (\%) & $1(3.3)$ & $1(8.3)$ & 1.000 \\
\hline Pacemaker (\%) & $1(3.3)$ & $0(0.0)$ & 1.000 \\
\hline Wound infection (\%) & & & 0.242 \\
\hline None & $164(95.3)$ & $87(96.7)$ & \\
\hline Superficial & $8(4.7)$ & $2(2.2)$ & \\
\hline Deep & $0(0.0)$ & $1(1.1)$ & \\
\hline Ventilation time, minutes (\%) & $2721.28(7779.54)$ & $4070.48(9294.47)$ & 0.231 \\
\hline ICU time, hours (\%) & $71.43(160.64)$ & $95.27(180.40)$ & 0.298 \\
\hline Hospital time, days (\%) & $9.95(8.39)$ & $9.84(6.82)$ & 0.916 \\
\hline
\end{tabular}


Apart from the obvious reasons, another consideration advocating for the delay of asymptomatic elective cases is the incubation period of COVID-19. A recent paper reported on patients who tested negative for COVID-19 during their asymptomatic incubation period and then underwent various surgical procedures. The mortality rate of these patients was dramatically high (20.5\%) [21]. Conversely, it could be argued that symptoms are subjective rather than objective parameters, and there might be some clinical discrepancies between NYHA and the severity of the disease.

One of the most intriguing facts demonstrated by this study emerged from the operative data. While there was no net difference in terms of types and complexity of procedures, patients from the COVID-19 era had longer procedural time. It could be that the cases selected in 2020 were more complex and challenging. However, it is difficult to ascertain whether the underlying reason for this is a more complex anatomy, late hospital arrival, or simply a coincidence.

Several factors may contribute to the higher rate of inhospital mortality for patients in the 2020 group (13\% vs. 5.2\%). The first is the aforementioned assumption of more challenging procedures. The second hypothesis is possibly related to late hospital arrival of patients during the COVID-19 pandemic, which may have worsened their underlying condition. With the pandemic progressing worldwide, panic grew within the population, and indeed patients avoided hospitals even at the cost of being symptomatic.

Lastly, cardiopulmonary bypass might have a deleterious effect on COVID-19 patients undergoing cardiac surgery. This is explained by an increased inflammatory response triggered by the non-endothelial surfaces of the pump [22]. However, as off-pump CABG is not routinely performed in our institute, this study was unable to evaluate a comparison between this possible effect of on-pump CABG.

May 2020 was a positive turning point in Israel concerning COVID-19. The "curve" seemed to be flattened and the number of new positive cases declined daily, together with the governmental restrictions including those concerning medical practices. This prompted the question of when to restore the daily routine in the field of interventional cardiology and cardiac surgery. In fact, the number of patients is growing on a daily basis and elective cases are now performed routinely. The safety of the medical teams remains the first priority, and the primary goal is to proactively manage all surgical cases including comprehensive COVID-19 screening protocol for both patients and personnel.

Now that the first major outbreak of COVID-19 seems to be fading away, cardiac surgeons must bear in mind that a second outbreak might be coming soon.
Therefore, it is imperative that cardiac surgery teams should be vigilant and learn from their own experience and the experience of others. It is a call for surgeons to be aware of the possible and probable impact of COVID-19 on non-COVID-19 patients.

\section{Conclusion}

COVID-19 is having an impact on both infected and non-infected patients. During the outbreak period, a smaller number of patients underwent cardiac surgery. These patients experienced more symptoms, had longer procedures, and had a higher in-hospital mortality rate. While the consequences of the pandemic are not fully understood, one thing is certain; we must prepare for a possible new outbreak.

\section{Abbreviations}

ARDS: acute respiratory distress syndrome; CABG: coronary artery bypass graft; COVID-19: coronavirus disease 2019; CSCS: Canadian Society of Cardiac Surgeons; ECMO: extracorporeal membrane oxygenation; NYHA: New York Heart Association; PCI: percutaneous cardiac intervention; SARS-CoV-2: severe acute respiratory syndrome coronavirus 2

\section{Acknowledgments}

Acknowledgment - not relevant.

\section{Authors' contributions}

Authors' contribution: all authors are surgeons. The first two authors contributed equally regarding data collection, statistical analysis and writing the manuscript. The author(s) read and approved the final manuscript.

\section{Funding}

This study had no funding.

\section{Availability of data and materials \\ Supporting data are available.}

Ethics approval and consent to participate

The study was approved by the hospital ethical committee. (patient's consent for participation - not relevant).

\section{Consent for publication}

All authors consent for publication.

Competing interests

No conflict of interest.

Received: 29 July 2020 Accepted: 28 September 2020

Published online: 02 October 2020

References

1. Driggin E, Madhavan MV, Bikdeli B, et al. Cardiovascular considerations for patients, health care workers, and health systems during the COVID-19 pandemic. J Am Coll Cardiol. 2020;75:2352-71.

2. Huang C, Wang Y, Li X, et al. Clinical features of patients infected with 2019 novel coronavirus in Wuhan, China. Lancet. 2020;395:497-506.

3. Organization $\mathrm{WH}$. WHO director- General's opening remarks at the media briefing on COVID-19-11 March 2020. WHO website: WHO, 2020.

4. Hassan A, Arora RC, Lother SA, et al. Ramping up the delivery of cardiac surgery during the COVID-19 pandemic: a guidance statement from the Canadian Society of Cardiac Surgeons. Can J Cardiol. 2020;36(7):1139-43. https://doi.org/10.1016/j.cjca.2020.04.030.

5. Wong J, Goh QY, Tan Z, et al. Preparing for a COVID-19 pandemic: a review of operating room outbreak response measures in a large tertiary hospital in Singapore. Can J Anaesth. 2020;67:732-45.

6. Organization WH. Infection prevention and control of epidemic- and pandemic-prone acute respiratory diseases in health care. WHO guidelines 
2007. https://www.who.int/csr/bioriskreduction/infection_control/ publication/en/. 2007.

7. Hassan A, Arora RC, Adams C, et al. Cardiac surgery in Canada during the COVID-19 pandemic: a guidance statement from the Canadian Society of Cardiac Surgeons. Can J Cardiol. 2020;36(6):952-55. https://doi.org/10.1016/j. cjca.2020.04.001. Epub 2020 Apr 8.

8. Murthy $\mathrm{S}$, Gomersall CD, Fowler RA. Care for critically ill patients with COVID-19. JAMA. 2020

9. Liu K, Fang YY, Deng Y, et al. Clinical characteristics of novel coronavirus cases in tertiary hospitals in Hubei Province. Chin Med J. 2020;133:1025-31.

10. Xu Z, Shi L, Wang Y, et al. Pathological findings of COVID-19 associated with acute respiratory distress syndrome. Lancet Respir Med. 2020;8:420-2.

11. Zhou F, Yu T, Du R, et al. Clinical course and risk factors for mortality of adult inpatients with COVID-19 in Wuhan, China: a retrospective cohort study. Lancet. 2020;395:1054-62.

12. Klok FA, Kruip M, van der Meer NJM, et al. Incidence of thrombotic complications in critically ill ICU patients with COVID-19. Thromb Res. 2020;191: 145-47. https://doi.org/10.1016/j.thromres.2020.04.013. Epub 2020 Apr 10

13. MacLaren G, Fisher D, Brodie D. Preparing for the most critically ill patients with COVID-19: the potential role of extracorporeal membrane oxygenation. JAMA. 2020;323(13):1245-46. https://doi.org/10.1001/jama.2020.2342.

14. Chen C, Zhou Y, Wang DW. SARS-CoV-2: a potential novel etiology of fulminant myocarditis. Herz. 2020;45:230-2.

15. Hong X, Xiong J, Feng Z, Shi Y. Extracorporeal membrane oxygenation (ECMO): does it have a role in the treatment of severe COVID-19? Int J Infect Dis. 2020:94:78-80.

16. Bartlett RH, Ogino MT, Brodie D, et al. Initial ELSO guidance document: ECMO for COVID-19 patients with severe cardiopulmonary failure. ASAIO J. 2020;66:472-4

17. Namendys-Silva SA. ECMO for ARDS due to COVID-19. Heart Lung. 2020; 49(4):348-9.

18. Tang N, Bai H, Chen X, Gong J, Li D, Sun Z. Anticoagulant treatment is associated with decreased mortality in severe coronavirus disease 2019 patients with coagulopathy. J Thromb Haemost. 2020;18:1094-9.

19. Wang $M$, Cao $R$, Zhang $L$, et al. Remdesivir and chloroquine effectively inhibit the recently emerged novel coronavirus (2019-nCoV) in vitro. Cell Res. 2020;30:269-71.

20. Gao J, Tian Z, Yang X. Breakthrough: Chloroquine phosphate has shown apparent efficacy in treatment of COVID-19 associated pneumonia in clinical studies. Biosci Trends. 2020;14:72-3.

21. Lei S, Jiang F, Su W, et al. Clinical characteristics and outcomes of patients undergoing surgeries during the incubation period of COVID-19 infection. EClinicalMedicine. 2020;21:100331. https://doi.org/10.1016/j.eclinm.2020. 100331. eCollection 2020 Apr.

22. Islam M. Shehata, Alan D. Kaye et al. Elective cardiac surgery during the COVID-19 pandemic: proceed or postpone? Best Pract Res Clin Anaesthesiol. 2020;34(3):643-50. https://doi.org/10.1016/j.bpa.2020.07.005

\section{Publisher's Note}

Springer Nature remains neutral with regard to jurisdictional claims in published maps and institutional affiliations.

Ready to submit your research? Choose BMC and benefit from:

- fast, convenient online submission

- thorough peer review by experienced researchers in your field

- rapid publication on acceptance

- support for research data, including large and complex data types

- gold Open Access which fosters wider collaboration and increased citations

- maximum visibility for your research: over $100 \mathrm{M}$ website views per year

At $\mathrm{BMC}$, research is always in progress.

Learn more biomedcentral.com/submissions 